\title{
Preparation of superconducting films by metal organic deposition
}

\section{- Research and development towards a fault current limiter and other electric devices -}

\author{
Takaaki MAnABE* , Mitsugu Sohma, Iwao Yamaguchi, Hiroaki MATsul, Tetsuo TsuchiYA and Toshiya Kumagal
}

[Translation from Synthesiology, Vol.7, No.4, p.247-257 (2014)]

\begin{abstract}
For the application of oxide superconductors to power-electric and microwave devices, it is necessary to form oxide superconductors into films and tapes. Since oxide superconductors are fragile and processing resistant, establishing a thin film processing technology for oxide superconductors is important. In this article, we describe our approach to developing such technology with an example that involves the processing of high quality large-size superconducting thin films by metal organic deposition (MOD) for the realization of a fault current limiter. MOD is a simple and low-cost processing technology for metal oxide thin films, which are prepared by dipping a substrate in a coating solution and firing the substrate.
\end{abstract}

Keywords : Metal organic deposition, superconductor, thin films, fault current limiter, microwave devices, coated conductor

\section{Background of the research}

\subsection{High-temperature oxide superconductor and its application to a fault current limiter (FCL)}

The high-temperature oxide superconductor that was discovered in 1986 was later found that its critical temperature (temperature at which superconductive condition is achieved and the electrical resistance is zero: $T_{c}$ ) can be increased to 90 $\mathrm{K}$ with the discovery of perovskite-type compound $\mathrm{YBa}_{2} \mathrm{Cu}_{3} \mathrm{O}_{7}$ (hereinafter will be called YBCO), and the expectation for its practical application rose since it can be used with lowcost liquid nitrogen (boiling point $77 \mathrm{~K}$ ) instead of expensive liquid helium (boiling point $4 \mathrm{~K}$ ). For example, if this material is processed into power transmission cables, the loss due to resistance during power transmission can be reduced, and it was calculated that the transmission loss can be kept at about half compared to copper wire even considering the energy needed for cooling. ${ }^{[1]}$

Various applications and devices, not just power transmission cables, can be realized by processing the superconductor into thin film form. One such device is the SN transition type (thin film type) fault current limiter (FCL). As it will be explained in chapter 2, FCL is a new kind of electrical device that instantly inhibits large overcurrent that may occur due to lightning strikes or tree falls on the transmission or distribution lines, thus facilitating the shutoff of accidental current (Fig. 1). ${ }^{[1][2]}$ Since the thin film type FCL (Fig. 2) is highly reliable and is capable of handling high voltage and large current, there is expectation for development toward high-volume interconnection of distributed power supply sites using low-cost superconducting film.

\subsection{Metal organic deposition (MOD) method}

The authors had been engaging in the development of ceramic thin film manufacturing process by the metal organic deposition (MOD) method before the discovery of hightemperature superconductors. MOD is a method of "coating and firing" where the metal organic compound containing the constituent elements are dissolved in an organic solvent, this solution is coated onto a substrate, and heat treatment is done to burn off the organic components to form the metal oxide film (Fig. 3). ${ }^{[3][4]}$

Since the MOD method is comprised of simple processes of "coating and firing" and does not require a large-scale device that produces high vacuum or high voltage, it has the following characteristics: (1) it is easy to accurately control the chemical composition of the film, (2) it uses relatively low temperature in the process, (3) it can be applied to large surface area substrates of various forms as well as tapes of long length, and (4) it has low environmental load since it emits only steam and carbon dioxide during complete combustion and does not emit harmful substances such as hydrogen fluoride as in the MOD method that uses metal trifluoroacetates as a raw material (TFA-MOD). ${ }^{[5]}$

This paper describes the approaches and methods that were employed to achieve the goal for meeting the product requirement. The technology was developed to create a high-

Advanced Manufacturing Research Institute, AIST Tsukuba Central 5, 1-1-1 Higashi, Tsukuba 305-8565, Japan * E-mail: manabe.t@aist.go.jp

Original manuscript received June 6, 2014, Revisions received July 25, 2014, Accepted August 11, 2014 
quality large-surface-area superconducting film using the MOD method for application to FCL, under "R\&D of the Core Technology for Superconducting AC Equipment" ${ }^{\text {[1] }}$ funded for the Technological Development for Diversification of Power Source of the New Energy and Industrial Technology Development Organization (NEDO) and others.

\section{Necessity for device against accidental current such as FCL, and the required specification for the superconducting film in the thin film type FCL}

It was mentioned in the previous chapter that one of the applications of the superconducting thin film is to the thin film resistive-type FCL. To meet the demands of electric power deregulation and power shortage, the grid interconnection is promoted in which the distributed power supply such as excess power from home generated sources are connected and operated using the distribution lines of the electric power companies. When the distributed power supply sites are connected, in cases of short-circuit accidents as shown in Fig. 1(a), large overcurrent (accidental current or fault current) flows through the grid system instantly, and this may cause whole area blackout, damage the distributed power generators, and harm power appliances. To avoid such accidental damages, expensive additions must be made to facilities such as changing the existing distribution lines and

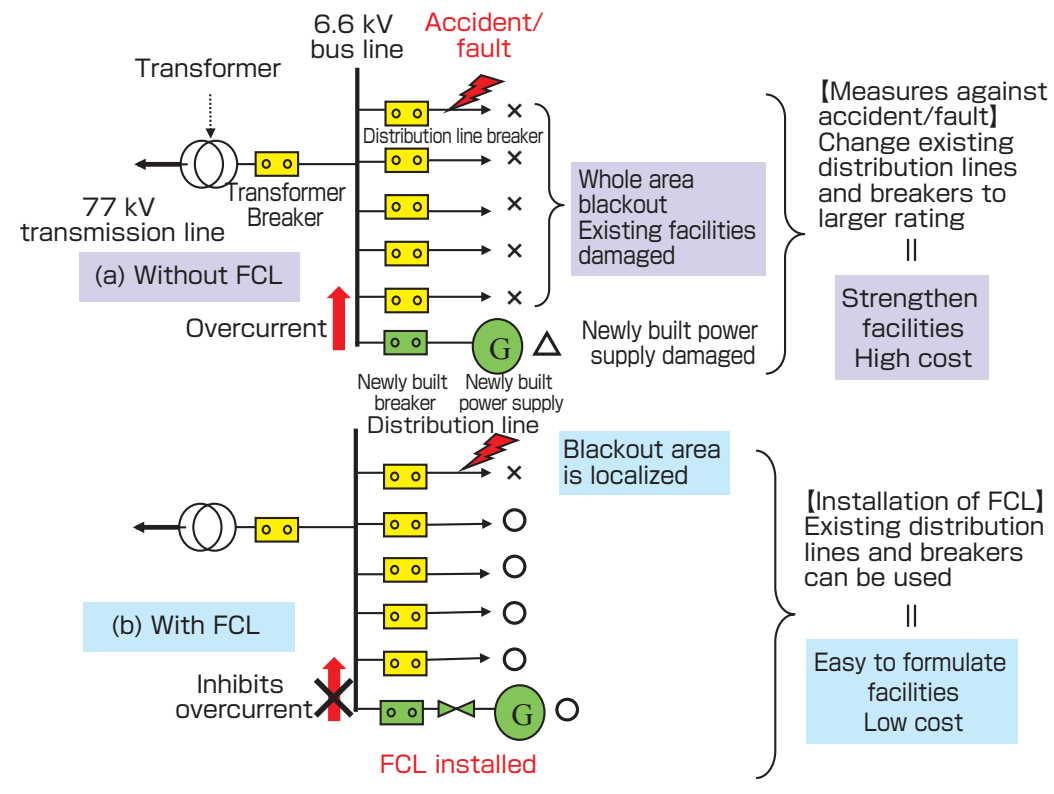

Fig. 1 Installation of FCL in distributed power supply site

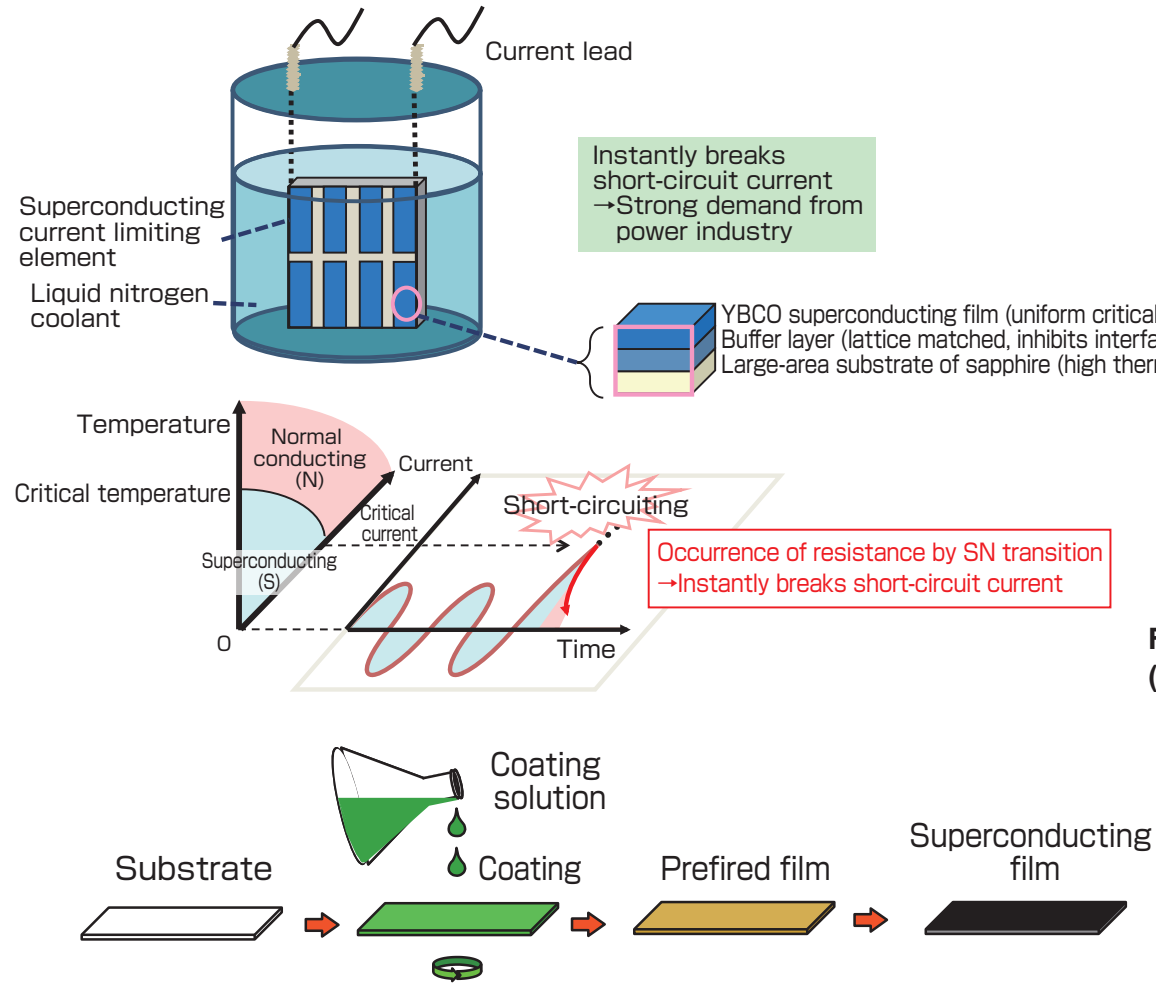

Fig. 2 Superconducting thin film FCL (SN transition type)
Fig. 3 Metal organic deposition (MOD) method 
breakers to ones with larger ratings. In contrast, when FCLs are introduced as shown in Fig. 1(b), the existing distribution lines and breakers can be used and the facilities can be laid out readily. Therefore, the realization of such FCLs is eagerly awaited. ${ }^{[1]}$ Here, FCL is a device that inhibits the overcurrent to flow into the circuit to protect the power network system (distribution and main lines) from fault current.

Currently, passive (autonomous action) FCLs including the thin film resistive-type and rectifier-type, as well as active FCLs such as the semiconductor switch type and arc driven type are being developed. The thin film resistive-type FCL (Fig. 2) is a type of passive FCL that uses the phenomenon where the superconducting thin film changes instantly from superconducting to normal conducting states and large resistance is generated when the overcurrent flows through the superconducting thin film (this phenomenon is called the SN transition or quenching) to inhibit the fault current. ${ }^{[6]}$ Since there are no moving parts in this method, it is reliable compared to active FCLs. Since the series-parallel arrangement of superconducting film is capable of handling high voltage and large current, there is expectation for the application to high-volume interconnection of distributed power supply sites using the low-cost superconducting film.

The functions required for the superconducting film for thin film resistive-type FCLs are as follows.

(1) Large critical current (current can flow in the superconducting state)

$\rightarrow$ Critical current density $\left(J_{c}\right.$ : hereinafter, critical current per $1 \mathrm{~cm}^{2}$ of cross section at $77 \mathrm{~K}$ ) must be high and the thin film be wide

(2) When it shifts to a normal conducting state, it must have high resistance and produce high voltage

$\rightarrow$ Thin film must be long in the direction of the current

The width and length of the superconducting film are related to the current and voltage, respectively, and the loss by the number of steps to obtain series-parallel arrangement and connection resistance increases as the number of sheets of superconducting film increases. Therefore, a superconducting film with high $J_{c}$ and a large surface area is necessary. The developmental goals of the "R\&D of the Core Technology for Superconducting AC Equipment" funded for the Technological Development for Diversification of Power Source were as follows: ${ }^{[7]}$

- High critical current density $\left(J_{c}>1,000,000 \mathrm{~A} / \mathrm{cm}^{2}\right)$

- A large surface area $(10 \mathrm{~cm} \times 30 \mathrm{~cm})$

Here, the $J_{c}$ value of the superconducting film is strongly dependent on the microstructure of the thin film, and it is necessary to have a single-crystal film where the YBCO particles are arranged three dimensionally to achieve high $J_{c}$. Therefore, it is necessary to manufacture a single-crystal superconducting thin film using the single-crystal with good lattice match (small difference of lattice constant) with YBCO as a substrate, and then epitaxially grow the YBCO on such a substrate. As it will be mentioned later, the sapphire (single-crystal alumina) substrate is highly regarded as the substrate for superconducting film for FCL from the perspective of thermal shock resistance and thermal conductivity. The largest size of commercially available sapphire was $10 \mathrm{~cm} \times 30 \mathrm{~cm}$. Since sapphire has poor lattice match with YBCO (about $10 \%$ mismatch) and reacts with $\mathrm{YBCO}$ at high temperature, it is necessary to form an appropriate buffer layer between the two. Also, the superconducting film must be thick to increase the critical current, but the thermal expansion coefficient of YBCO (13 $\left.\times 10^{-6} / \mathrm{K}\right)$ is about twice that of sapphire $\left(5 \sim 7 \times 10^{-6} / \mathrm{K}\right){ }^{[8][9]}$ When the film thickness of YBCO surpasses $300 \mathrm{~nm}$ (critical film thickness), micro-cracks may occur due to heat stress when cooling from the deposition temperature $\left(700 \sim 800{ }^{\circ} \mathrm{C}\right)$, and therefore, the film thickness that can be obtained with sapphire is $300 \mathrm{~nm}$ or less.

\section{Comparison of the MOD method and conventional large-area deposition technology and the scenario to realize the goal}

As it is clear from chapter 2, the establishment of synthesis technology for large-area superconducting films with high $J_{c}$ is necessary for the development of thin film resistive-type FCLs. Meanwhile, the authors have been engaging in the research of a YBCO thin film preparation process using the MOD method immediately after the discovery of YBCO. In this chapter, we shall describe the R\&D scenario to achieve the goal for the product requirement extracted in chapter 2, when preparing the large-area superconducting film by the MOD method for FCL application, after comparing the MOD and the conventional large-area deposition technologies.

\subsection{Comparison of the MOD method and other large- area deposition technologies ${ }^{[3][4]}$}

As shown in Fig. 3, the MOD method and the conventional large-area deposition technologies for metal oxides can be compared as follows.

\section{1) Conventional technology}

(1) Gas phase method (vacuum evaporation, pulsed laser deposition (PLD), sputtering, and chemical vapor deposition): The component atoms (molecules) are dissociated in the gaseous phase and then deposited on a substrate. Dense and good quality epitaxial film can be manufactured.

(2) Liquid phase method (slurry coating, sol-gel): The slurry, in which the powder of the target substance is dispersed in a solvent or a sol where a metal alkoxide is hydrolytically polycondensed, is coated onto a substrate, dried, and fired to manufacture a ceramic film. 
2) Problems of the conventional method

(1) The gas phase method requires the simultaneous control of the processes of gas production and deposition on the substrate, and therefore, controlling the composition and achieving large surface areas are difficult. Also, since high vacuum and high voltage are necessary, expensive facilities and a large amount of power are required, thus making the process costly and energy consuming.

(2) As powder or gel formed by drying sol is fired, the liquid phase method results in a polycrystalline, nonoriented film with low performance.

It is possible to obtain an epitaxial film with high $J_{c}$ by the gas phase method, but it is expensive and may generate non-uniformity in a large surface area. Conventionally, the maximum size of a YBCO film manufactured by the gas phase method is: $20 \mathrm{~cm}$ in diameter (with a non-deposited area in the center) and $10 \mathrm{~cm} \times 20 \mathrm{~cm}$ (substrate transfer in one direction) by co-evaporation; ${ }^{[10]} 7 \mathrm{~cm} \times 20 \mathrm{~cm}$ by PLD; ${ }^{[12]}$ and $7 \mathrm{~cm}$ in diameter by sputtering. ${ }^{[13]}$ On the other hand, the liquid phase method enables the production of a low-cost, uniform, large-area film, but it will be polycrystalline, nonoriented, and have low $J_{c}$.

\subsection{Scenario to achieve the goal}

In this study, R\&D was conducted using a scenario divided into the following two stages to achieve the goal to fulfill the product requirement extracted in chapter 2 .

I. Demonstration of YBCO thin film manufacturing and achievement of high $J_{c}$

II. Deposition of a high- $J_{c}$ large-area YBCO film

When discussing the research of the superconducting film deposition by the MOD method in chronological order, initially only Scenario I was the goal of development. There was fierce international competition to develop the superconducting film deposition technology by a solution method immediately after the discovery of the YBCO superconductor. The authors were able to demonstrate the zero resistance of the YBCO film ahead of other research institutions and were able to file the patent. Immediately after the discovery of the YBCO superconductor, development in Josephson elements for thin film application and superconducting wire rods, coils, magnets, and others in the thick film application were discussed, but the achievement of high $J_{c}\left(>1000,000 \mathrm{~A} / \mathrm{cm}^{2}\right)$ was required in all these applications. Figure 4 shows the diagram of the research scenario at this point.

When the firing temperature is high, a chemical reaction occurs at the interface between the YBCO film and the substrate, and therefore a low-temperature process was developed to inhibit this interface reaction. Then, a latticematched substrate that became available due to lowprocessing temperature was used to increase the orientation capability of the YBCO film, epitaxial film was formed unexpectedly even though it was through a solution method, and high $J_{c}$ was obtained. The outline of this process will be discussed in the next chapter.

When it became apparent that the epitaxial YBCO film could be manufactured in Scenario I, the talks began of power deregulation and large-volume interconnection of distributed power supply sites. Since the superconducting film FCL became hopeful in strengthening the durability of the electrical devices for high-volume interconnection of dispersed power at low cost, the core technology for "epitaxial YBCO deposition and achievement of high $J_{c}$ " obtained in Scenario I was expanded to set Scenario II. However, many difficulties were predicted in manufacturing the large-area YBCO film with high $J_{c}$ all at once, and the R\&D was done concurrently to achieve the goals of II-1 and II-2 as follows. Ultimately, Goal II-3 would be achieved to fulfill the product requirement extracted in chapter 2 .

II-1 Achievement of large-area YBCO deposition on lattice-matched substrates

II-2 Multilayer deposition of buffer and superconducting layers on sapphire (lattice-mismatched) substrates

II-3 Manufacture of a large-area film with superconducting/ buffer/sapphire multilayers

This scenario is shown in Fig. 5 and the outline will be explained in chapter 5 . Table 1 shows the outlines of the elemental technologies that were necessary to achieve the goals in Scenario I and II for manufacturing the superconducting film, and the elemental technologies that played a major role in achieving the goals are framed by thick lines.

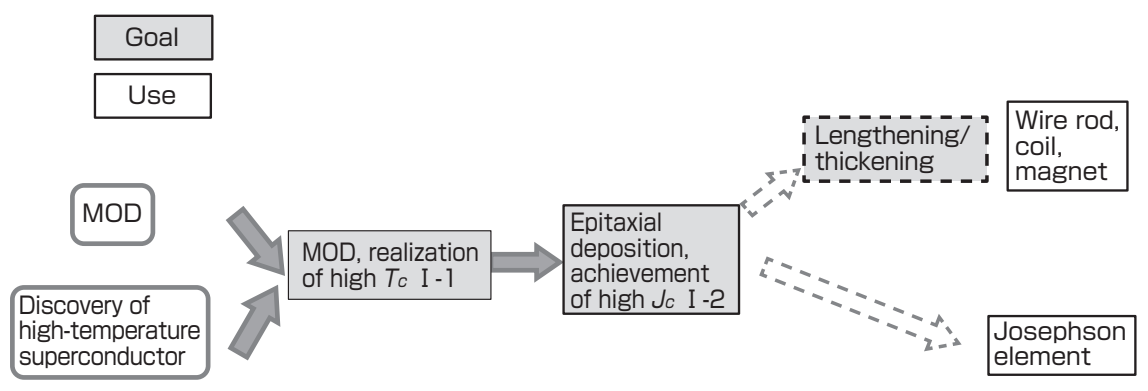

Fig. 4 Scenario I for the manufacture of high- $J_{c}$ superconducting film by MOD 
Table 1. Elemental technologies to achieve the goals in Scenario I and II for the manufacture of superconducting film

\begin{tabular}{|c|c|c|c|c|c|c|c|}
\hline GOAL & $\begin{array}{l}\text { SUBSTRATE, } \\
\text { TYPE, SIZE }\end{array}$ & $\begin{array}{l}\text { BUFFER } \\
\text { LAYER }\end{array}$ & SOLUTION & COATING & PREFIRING & $\begin{array}{l}\text { FINAL HEAT } \\
\text { TREATMENT }\end{array}$ & USE \\
\hline $\begin{array}{l}\text { I - 1 : } \\
\text { MOD, realization } \\
\text { of high } T_{c}\end{array}$ & $\begin{array}{l}\text { Selection of } \\
\text { low-reactive substrate } \\
\text { YSZ.12 } \\
25 \times 25 \mathrm{~mm}^{2}\end{array}$ & - & \begin{tabular}{|l|} 
Search of \\
raw material \\
and solvent
\end{tabular} & Dip coating & $\begin{array}{l}\text { Thermal } \\
\text { decomposition }\end{array}$ & $\begin{array}{l}\text { Search of heat } \\
\text { treatment } \\
\text { condition in } \\
\text { oxygen }\end{array}$ & \\
\hline $\begin{array}{l}\text { I -2 : } \\
\text { Achievement of } \\
\text { high } J_{c}\end{array}$ & $\begin{array}{l}\text { Lattice-matched } \\
\text { single crystal } \\
\text { STO.5x10 mm² }\end{array}$ & - & $\begin{array}{l}\text { Solution } \\
\text { tuning }\end{array}$ & Spin coating & $\begin{array}{l}\text { Thermal } \\
\text { decomposition }\end{array}$ & $\begin{array}{l}\text { Development of } \\
\text { low-oxygen } \\
\text { low-temperature } \\
\text { process }\end{array}$ & $\begin{array}{l}\text { (Josephson } \\
\text { element) }\end{array}$ \\
\hline $\begin{array}{l}\text { П-1 : } \\
\text { Primary } \\
\text { achievement of } \\
\text { large surface area }\end{array}$ & $\begin{array}{l}\text { Large-area } \\
\text { lattice-matched } \\
\text { single crystal } \cdot \text { STO, } \\
\text { LAO } 2 \text { cm } \Phi, 5 \mathrm{~cm} \Phi\end{array}$ & & $\begin{array}{l}\text { Solution } \\
\text { tuning }\end{array}$ & Spin coating & $\begin{array}{l}\text { Thermal } \\
\text { decomposition }\end{array}$ & $\begin{array}{l}\text { Low-oxygen } \\
\text { low-temperature } \\
\text { process (infrared } \\
\text { heating) }\end{array}$ & \\
\hline $\begin{array}{l}\text { II -2 : } \\
\text { Consideration of } \\
\text { multilayer } \\
\text { process }\end{array}$ & $\begin{array}{l}\text { Lattice-mismatched } \\
\text { single crystal. } \\
\text { sapphire } \cdot 2 \times 2 \mathrm{~cm}^{2}\end{array}$ & $\begin{array}{l}\mathrm{CeO}_{2} \\
\text { vapor } \\
\text { deposition }\end{array}$ & $\begin{array}{l}\text { Solution } \\
\text { tuning }\end{array}$ & Spin coating & $\begin{array}{l}\text { Thermal } \\
\text { decomposition }\end{array}$ & $\begin{array}{l}\text { Low-oxygen } \\
\text { low-temperature } \\
\text { process (tubular } \\
\text { furnace) }\end{array}$ & \\
\hline $\begin{array}{l}\text { II -3: } \\
\text { Achievement of } \\
\text { large-area } \\
\text { multilayer }\end{array}$ & $\begin{array}{l}\text { Large-area } \\
\text { lattice-mismatched } \\
\text { single crystal·sapphire } \\
1 \times 12 \mathrm{~cm}^{2}, 3 \times 21 \mathrm{~cm}^{2} \\
10 \times 30 \mathrm{~cm}^{2}\end{array}$ & $\begin{array}{l}\text { Large-area } \\
\mathrm{CeO}_{2} \\
\text { vapor } \\
\text { deposition }\end{array}$ & $\begin{array}{l}\text { Solution } \\
\text { tuning }\end{array}$ & $\begin{array}{l}\text { Large-area } \\
\text { spin coating }\end{array}$ & $\begin{array}{l}\text { Thermal } \\
\text { decomposition }\end{array}$ & $\begin{array}{l}\text { Low-oxygen } \\
\text { low-temperature } \\
\text { process } \\
\text { (large-area } \\
\text { tubular furnace) }\end{array}$ & $\mathrm{FCL}$ \\
\hline $\begin{array}{l}\text { II }-4 \text { : } \\
\text { Achievement of } \\
\text { low Rs, patterning }\end{array}$ & $\begin{array}{l}\text { Low permittivity } \\
\text { substrate·LAO, } \\
\text { LSAT } \cdot \text { sapphire } \\
\text { 2x2 } \mathrm{cm}^{2}, 5 \mathrm{~cm} \Phi\end{array}$ & $\begin{array}{l}{\left[\mathrm{CeO}_{2}\right.} \\
\text { vapor } \\
\text { deposition] }\end{array}$ & $\begin{array}{l}\text { Solution } \\
\text { tuning }\end{array}$ & Spin coating & $\begin{array}{l}\text { Irradiation. } \\
\text { thermal } \\
\text { decomposition } \\
\text { (ELAMOD) }\end{array}$ & $\begin{array}{l}\text { Low-oxygen } \\
\text { low-temperature } \\
\text { process }\end{array}$ & $\begin{array}{l}\text { Microwave } \\
\text { filter }\end{array}$ \\
\hline $\begin{array}{l}\text { II -5 : } \\
\text { Lengthening/ } \\
\text { thickening, } \\
\text { Achievement of } \\
\text { high /c }\end{array}$ & $\begin{array}{l}\text { Textured metal. } \\
\text { Ni-W etc. } \\
1 \mathrm{~cm} \text { width }\end{array}$ & $\begin{array}{l}\mathrm{CeO}_{2} \\
\text { vapor } \\
\text { deposition }\end{array}$ & $\begin{array}{l}\text { Coating } \\
\text { solution for } \\
\text { thick films, } \\
\text { flux pinning }\end{array}$ & $\begin{array}{l}\text { Dip coating } \\
\text { etc. }\end{array}$ & $\begin{array}{l}\text { Irradiation. } \\
\text { thermal } \\
\text { decomposition } \\
\text { (ELAMOD)? }\end{array}$ & $\begin{array}{l}\text { Low-oxygen } \\
\text { low-temperature } \\
\text { process }\end{array}$ & Wire rod \\
\hline
\end{tabular}

\section{Demonstration of YBCO thin film manufacturing and achievement of high $J_{c}$}

In this chapter, the outline for achieving the high $J_{c}$ in Scenario I shown in Fig. 4 will be explained.

\subsection{Preparation of the solution and the demonstration of YBCO deposition by heat treatment in oxygen}

As shown in Table 1, to achieve Goal I-1, the search for starting materials and solvents for the coating solution, the pursuit of heat treatment conditions, and the selection of lowreactive substrates were the major developmental elements.

In general, the metal organic compounds with different electronegativity tend to have different solubility, and it is difficult to prepare a homogeneous solution in a multicomponent system. In this research, solvent search was conducted using the organic compounds with characteristic structures (ones with side chains or acting as ligands) as starting materials and changing the types of solvents (hydrocarbon, alcohol, acid, ketone, aldehyde, ester, and nitrogen compounds) or their chain lengths. As a result, we were able to create a coating solution in which the $\mathrm{Y}, \mathrm{Ba}$, and $\mathrm{Cu}$ were homogeneously dissolved in high concentration. This solution was applied to the substrate, thermally decomposed at $500{ }^{\circ} \mathrm{C}$ in an ambient atmosphere to form a prefired film composed of $\mathrm{Y}_{2} \mathrm{O}_{3}-\mathrm{BaCO}_{3}-\mathrm{CuO}$. The final heat treatment and solid-phase reaction were done at 950 ${ }^{\circ} \mathrm{C}$ in oxygen as in the sintered compact, and we succeeded in demonstrating the YBCO film preparation ${ }^{[14][15]}$ and obtained the basic patent for the solution and the manufacturing method. However, since the final heat treatment temperature was high, we were unable to obtain a YBCO film on the lattice-matched single-crystal substrates with a perovskite structure such as strontium titanate $\left(\mathrm{SrTiO}_{3}\right.$, lattice mismatch: about $\left.1 \%\right)$ since

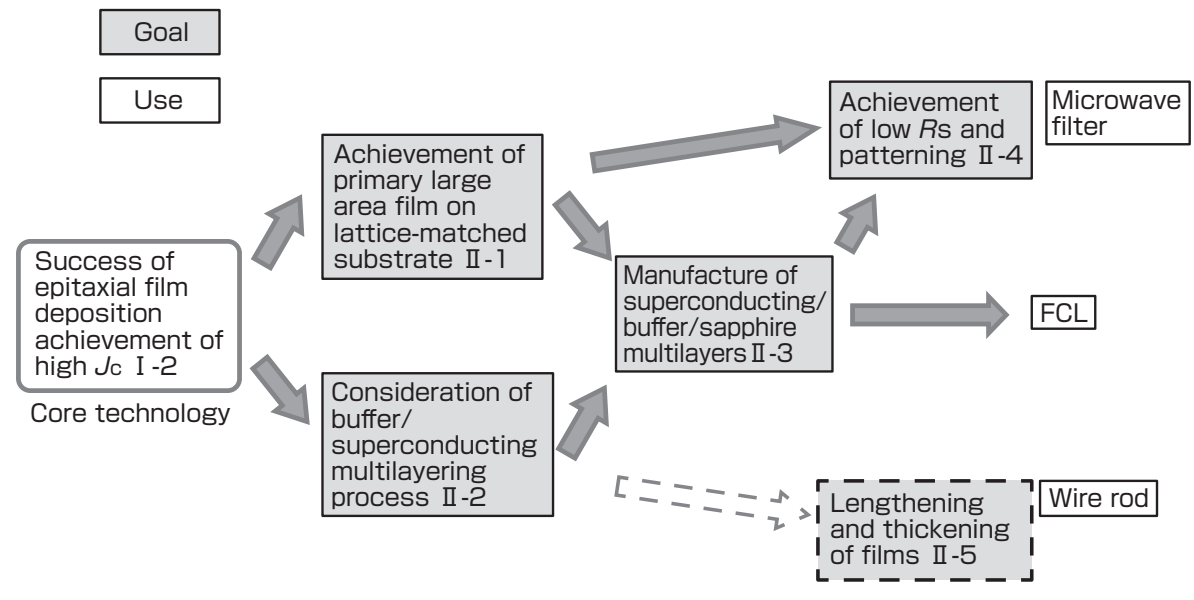

Fig. 5 Scenario II for the manufacture of large-area superconducting film for FCL 
it reacted with $\mathrm{BaCO}_{3}$ in the prefired film. We obtained $T_{c}=90$ $\mathrm{K}$ only when the yttria-stabilized zirconia sintered compact with low reactivity was used as the substrate, but the film was polycrystalline, and the $J_{c}$ at liquid nitrogen temperature $(77 \mathrm{~K})$ was low $\left(\sim 1000 \mathrm{~A} / \mathrm{cm}^{2}\right){ }^{[16]}$

\subsection{Development of a low-temperature process and achievement of high $\mathrm{J}_{c}$}

The development of a low-temperature process using lowoxygen pressure was the most important point in achieving Goal I-2.

Since the superconductivity is lost when the high-temperature oxide superconductor is deprived of oxygen, it was conventionally fired in oxygen. The authors obtained the hint from the study by Kishio et al., ${ }^{[17]}$ and considered that the valence control of functional oxides that contain transition metals such as YBCO was important, and heat treatment must be done by controlling the oxygen partial pressure $\left(p \mathrm{O}_{2}\right)$ and temperature $(T)$. Therefore thermal analysis was conducted by changing the $p \mathrm{O}_{2}$ for the powder obtained by thermal decomposition (or prefiring) of the coating solution. As a result of x-ray diffraction of the product, it became apparent that the production temperature of YBCO could be decreased by 100 ${ }^{\circ} \mathrm{C}$ or more by using low oxygen pressure. ${ }^{[18]}$

In the heat treatment at maximum temperature of around $700{ }^{\circ} \mathrm{C}$, the reaction between the YBCO and a lattice-matched singlecrystal substrate such as $\mathrm{SrTiO}_{3}$ could be sufficiently suppressed, and the YBCO film was formed on the $\mathrm{SrTiO}_{3}$ substrate. To improve the uniformity and reproducibility of the thickness of the film product, the solution was applied using a spin coater ${ }^{[19]}$ and prefiring was done at $500{ }^{\circ} \mathrm{C}$ in an ambient atmosphere.

Next we succeeded in decreasing the temperature by about $200{ }^{\circ} \mathrm{C}$ from the maximum temperature of the conventional heat process by optimizing the oxygen partial pressure and the heating rate for the final heat treatment of the prefired film (development of the low-temperature process). Figure 6 shows the schematic representation of the stable range of $\mathrm{YBCO}$ and copper oxides $\left(\mathrm{Cu}_{2} \mathrm{O}-\mathrm{CuO}\right)$ on the Ellingham diagram, with the logarithm of oxygen partial pressure $\left(p \mathrm{O}_{2}\right)$ and the reciprocal of temperature $(1 / T)$ as the two axes (orientation will be discussed in the next chapter). ${ }^{[20]}$ Here, the conventional heat process in oxygen corresponded to Route I-1, while the lowtemperature process to Route I-2. Since low-oxygen pressure was used in Route I-2, the non-superconductor $\mathrm{YBa}_{2} \mathrm{Cu}_{3} \mathrm{O}_{6}$ with less oxygen was produced in the final heat treatment, but by switching to $1 \mathrm{~atm}$ oxygen after the final heat treatment and allowing the oxygen to be incorporated into the crystal during cooling, it converted to superconductor $\mathrm{YBa}_{2} \mathrm{Cu}_{3} \mathrm{O}_{7}$. Moreover, as an amazing finding at the time, the YBCO film manufactured in Route I-2 grew epitaxially on the substrate even though it started from the solution, and a $J_{c}$ of $1,000,000$ $\mathrm{A}(=1 \mathrm{MA}) / \mathrm{cm}^{2}$, which is equivalent to that of the YBCO film made by the gas-phase method was achieved at $77 \mathrm{~K}$. Hence, Goal I-2 was achieved. ${ }^{[21][22]}$

\section{Deposition of a large-area YBCO film with high $J_{c}$}

In this chapter, setting the "success of epitaxial film formation, achievement of high $J_{c}$ " of Scenario I-2 as core technology, the outline up to the realization of high- $J_{c}$ largearea film by Scenario II as shown in Fig. 5 is explained.

The YBCO film prepared on $\mathrm{SrTiO}_{3}$ substrate in chapter 4 was of a small size of $5 \mathrm{~mm} \times 10 \mathrm{~mm}$. Due to the reactivity of the substrate and the film as well as due to lattice mismatch, it was difficult to concurrently achieve the deposition on a large-area sapphire (single-crystal alumina) substrate that was desirable for FCL, as there was strong demand and desire to test the performance of the large-area YBCO film as soon as possible. Therefore, it was decided that, as shown in Scenario II in Fig. 5, while attempting to primarily increase the surface area of the YBCO film on the latticematched substrate, II-1, the manufacture of a buffer layer on the sapphire and tuning of YBCO deposition was conducted concurrently, II-2, and the enlargement of superconductor/ buffer/sapphire layer was done afterwards, II-3.

\subsection{Achievement of large-area deposition on the lattice-matched substrate}

For the achievement of Goal II-1, the selection of optimal heating rate in the low-temperature process was the main issue.

When the surface area of the lattice-matched substrate was increased, $J_{c}$ tended to decrease compared to the smaller

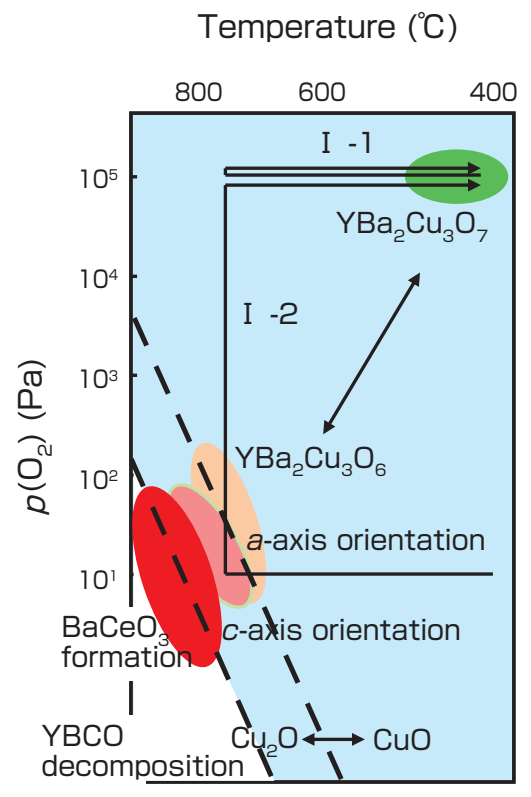

Fig. 6 Orientation and reaction of the YBCO film in the Ellingham diagram 
substrate even under the same heat treatment conditions. Initially, we did not know the reason for this, but referring to the Ellingham diagram in Fig. 6, it was revealed that there were areas in which the YBCO films readily become $c$-axis oriented (orientation that the superconducting current easily flows) with high $J_{c}$ around the temperature of thermal decomposition of $\mathrm{YBCO}$ and $\mathrm{CuO}$, and areas in which the YBCO films readily become $a$-axis oriented (orientation that the superconducting current does not easily flow) with low $J_{c}$ in the low-temperature side or areas of high oxygenpartial pressure, just as in the gas phase method. ${ }^{[23][24]}$ Using this property, the $c$-axis oriented film is deposited in the $c$-axis oriented area by the gas phase method. ${ }^{[25]}$ On the other hand, in the MOD method, since the prefired film that was once deposited underwent final heat treatment, the crystal growth of the $a$-axis grains is likely to occur locally as the substrate surface area increased as it passed through the $a$-axis oriented area in the heat process in the ordinary electrical furnace with a small heating rate. It was thought that the inclusion of the $a$-axis orientation occurred due to this phenomenon.

Therefore we introduced an infrared image furnace that enabled rapid heating. As a result of investigation on the heating rate and uniform heating conditions, the $c$-axis oriented film was obtained by rapid heating, i.e., by quickly passing the low-temperature zone where the $a$-axis orientation tended to occur and the $a$-axis oriented growth was inhibited. The YBCO film with a thickness of 700 $\mathrm{nm}$ manufactured on the lattice-matched $\mathrm{LaAlO}_{3}(\mathrm{LAO}$, mismatch about $2 \%$ ) with a diameter of $5 \mathrm{~cm}$ was extremely dense and smooth, and $J_{c}$ measured by the inductive method was extremely high $\left(>2 \mathrm{MA} / \mathrm{cm}^{2}\right) \cdot{ }^{[26][27]}$ Even with rapid heating, since YBCO and $\mathrm{LAO}$ are lattice matched and the thermal expansion coefficients are close (YBCO: $13 \times$ $10^{-6} / \mathrm{K}$; LAO: $\left.12.6 \times 10^{-6} / \mathrm{K}^{[9]}\right)$, no cracks occurred. Thus, it was possible to obtain a YBCO thick film with high $J_{c}$ on a lattice-matched LAO substrate. However, the maximum size that can be manufactured for a LAO substrate is about $5 \mathrm{~cm}$ in diameter, and a larger surface area cannot be obtained. Also, the thermal shock resistance and heat conductivity are low, and the substrate tends to be damaged due to heat stress when it is cooled in liquid nitrogen in the quenching process, and therefore it is considered unsuitable for FCL application.

\subsection{Formation of a buffer film on a sapphire (lattice- mismatched) substrate}

As a substrate material for superconducting films for FCL application, sapphire (single-crystal alumina) is optimal since heat conductivity and thermal shock resistance are high and large-surface area substrate is available. However, sapphire chemically reacts with YBCO, has a different crystal structure, and has large lattice mismatch (about $10 \%$ ), and these make the direct epitaxial growth of YBCO difficult. Therefore, similar to the gas phase methods, ${ }^{[10]-[13]} \mathrm{CeO}_{2}$ (lattice mismatch of about $1 \%$ ) was used as the buffer layer to mitigate the lattice mismatch as well as to inhibit chemical reaction.

When the $\mathrm{CeO}_{2}$ buffer layer was formed by a vacuum vapor deposition method by changing the deposition conditions (temperature, deposition rate, oxygen pressure, and plasma gasification conditions) on the sapphire substrate, the orientation of the $\mathrm{CeO}_{2}$ could be arranged in desirable directions (100) by plasma gasification of oxygen by a radiofrequency (RF) antenna and by increasing the substrate temperature. Then, the $\mathrm{CeO}_{2}$ buffer layer with a smooth surface at nanometer level could be obtained. ${ }^{[28][29]}$

Concurrent to the buffer layer deposition, we attempted tuning with the YBCO deposition by the MOD method on the buffer layer. Although the heat treatment condition was about the same as on the lattice-matched substrate, when $\mathrm{CeO}_{2}$ was used for the buffer layer, the production of $\mathrm{BaCeO}_{3}$ by reaction with $\mathrm{YBCO}$ became an issue. When $\mathrm{BaCeO}_{3}$ is produced, the amount of $\mathrm{Ba}$ in the film decreases, and not only does the metal composition ratio depart from 1:2:3 but also the crystallization property of YBCO decreases and the superconductivity degrades significantly. When we investigated the heat-treatment condition of the YBCO film when the $\mathrm{CeO}_{2}$ buffer layer was used, it was found that $\mathrm{BaCeO}_{3}$ was likely to be produced in high temperature or low oxygen partial pressure side, as shown in Fig. 6. It was also found during the optimization of the YBCO deposition condition on the $\mathrm{CeO}_{2}$ buffer layer, that although $\mathrm{CeO}_{2}$ had small lattice mismatch with YBCO, it had a fluorite-type crystal structure that was different from $\mathrm{YBCO}$, and the YBCO crystal growth rate became relatively small on $\mathrm{CeO}_{2}$. Therefore, no rapid heating using the infrared image furnace was required as in the lattice-matched substrate, and only heating with a tubular furnace was necessary. As a result of tuning the buffer layer deposition method and the heat treatment conditions, we succeeded in depositing YBCO with high $J_{c}$ at maximum heat-treatment temperature of about $750{ }^{\circ} \mathrm{C}$, with a $\mathrm{CeO}_{2}$ buffer layer of $40 \mathrm{~nm}$ (achievement of Goal II-2). ${ }^{[30][31]}$

\subsection{Achievement of large-area superconducting/ buffer/sapphire multilayers}

Next, we attempted to deposit the buffer layer on a largearea sapphire substrate and to form the superconducting multilayer on this layer. Here, the key issue was the uniformity of thickness of both layers deposited and of temperature and atmosphere of heat treatment.

For the buffer layer deposition, two vapor deposition sources were installed to improve uniformity, the decrease of substrate temperature was prevented by devising a heater and shield, and oxygen was plasma activated by a RF antenna. By increasing the power of RF and maintaining the substrate 
temperature high, we obtained a $\mathrm{CeO}_{2}$ film with a large surface that was smooth and uniform at nanometer level. ${ }^{[28][29]}$

We introduced a spin coater to handle large substrates for the large-area YBCO deposition, and a coating solution that was tuned for viscosity and evaporation rate to ensure even film thickness was applied. Next, in the prefiring process, totally uniform prefired film was obtained using a large muffle or tubular furnace in which the heating rate and the atmosphere were controlled. From the result of subchapter 5.2, it became apparent that rapid heating using the infrared image furnace was not necessary for the final heat treatment, and we succeeded in manufacturing a high-performance YBCO film on a large-area sapphire substrate of $10 \mathrm{~cm} \times 30$ $\mathrm{cm}$ size, by conducting precise temperature and atmosphere control using a large tubular furnace with high temperature uniformity (Fig. 7). It was on average $J_{c}=2.6 \mathrm{MA} / \mathrm{cm}^{2}$ as obtained in the inductive method, and the uniformity of average $J_{c}$ within $\pm 20 \%$ range was obtained for the majority of the measurement points. The goal value of the project in chapter 2 was achieved (II-3). ${ }^{[31]-[33]}$

\section{Later development}

Up to the previous chapter, we described the development of the synthesis technology of the large-area superconducting film by the MOD method. In this chapter, we shall discuss the later development: (1) the result of manufacturing the fault current limiting element using the superconducting film developed in this research, in a joint research with external institutions (companies, universities, and the Central Research Institute of Electric Power Industry) and a research group within AIST (jointly with Energy Technology Research Institute), and then creating a prototype FCL by a series-parallel arrangement and conducting the current limiting test; and (2) the application to microwave devices and wire rods. Please refer to the references for details.

\subsection{Prototype FCL test}

The superconducting films for the element were prepared by depositing on the $\mathrm{CeO}_{2} /$ sapphire substrate of $3 \mathrm{~cm} \times 21 \mathrm{~cm}$

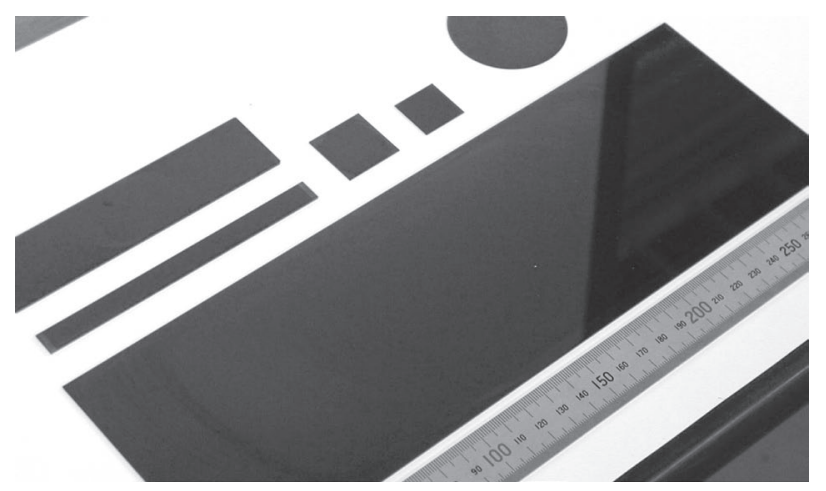

Fig. 7 Large-area YBCO films manufactured on substrates of various forms size with high throughput and uniformity, and a gold-silver alloy shunt layer with high resistance was formed to increase the voltage produced after quenching. ${ }^{[34]}$

(1) Joint research: mockup device (Fig. 8)

The $6.6 \mathrm{kV}$ class single-phase FCL unit, in which six units of two parallel elements were connected in series, was used to limit the peak current of $11.3 \mathrm{kA}$ to $4.5 \mathrm{kA}$. Based on this result, conceptual design of the $6.6 \mathrm{kV}$ class triple-phase FCL was done. ${ }^{[35]}$

\section{(2) AIST research:}

The $500 \mathrm{~V} / 200$ A single-phase FCL unit that used the noninductive shunt resistance developed by AIST was used to limit the peak current of $3.5 \mathrm{kA}$ to $770 \mathrm{~A} \cdot{ }^{[36]}$

The cost of the large-area superconducting film used for FCL in the dispersed distributed power supply site was calculated, and it was shown that in the future it will be lower than the target cost of realization. ${ }^{[37]}$

Based on these results, the technological transfer to companies of the large-area superconducting film manufacturing process is being promoted.

\subsection{Application to microwave devices and wire rods and tapes}

(1) Microwave filter for mobile communication base station Since the high-temperature superconductor has lower surface resistance than metal in the microwave range, call-enabled areas can be expanded and effect of electromagnetic wave can be decreased by increasing the communication quality by incorporating a filter made from a superconducting film into the mobile communication base station system. ${ }^{[38][39]}$ Here, the goals (II-4) required for the superconducting film are doublesided deposition on a large-area (5 $\mathrm{cm}$ in diameter), lowpermittivity substrate, low surface resistance, and patterning. The authors obtained the following results for the application to this field.

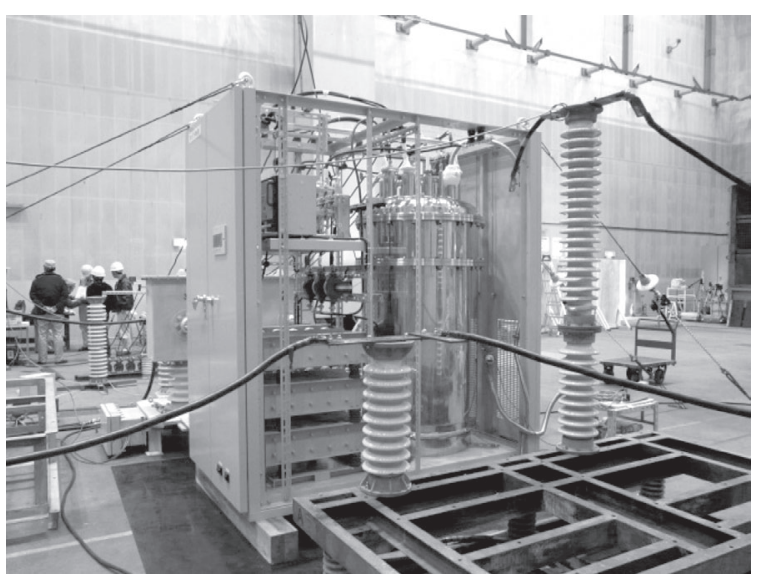

Fig. 8 6.6 kV single-phase FCL prototype 
a. Manufacture of microwave filter on a $2 \mathrm{~cm} \times 2 \mathrm{~cm}$ $\mathrm{LaAlO}_{3}$ substrate and verification of filter performance ${ }^{[40]}$

b. Achievements of YBCO deposition on a $5 \mathrm{~cm}$ diameter $\mathrm{LaAlO}_{3}$ substrate and low surface resistance ${ }^{[41]}$

c. Achievements of double-sided YBCO deposition on a 5 $\mathrm{cm}$ diameter $\mathrm{CeO}_{2} /$ sapphire substrate and low surface resistance $^{[42]}$

d. Possibilities of YBCO deposition by excimer-laserassisted MOD (ELAMOD) and concurrent patterning ${ }^{[43]}$

(2) Application to wire rods and tapes

The YBCO superconducting wires and tapes with long length and thickness were achieved by chemical vapor deposition (CVD) and TFA-MOD using trifluoroacetate (TFA) as the raw material. The MOD method discussed in this research is called the fluorine free (FF) MOD method since it does not include harmful fluorine in the raw material, and is expected to become a manufacturing method for superconducting wire rods and tapes at low cost and low environmental load. The authors have been conducting research with the goal of developing high critical current $\left(I_{c}\right)$ films (high $J_{c}$ and thick film) on oriented metal substrates that can be made long (Goal II-5), and the following results have been obtained to present.

a. Development of a thick coating solution: $0.8 \mu \mathrm{m}$ was achieved by a single coat and firing ${ }^{[44]}$

b. Manufacture of a thick film by repetition of the whole MOD process that includes coating, prefiring, and final heat treatment: manufactured a $4-\mu \mathrm{m}$-thick epitaxial film c. Achievement of high $I_{c}(>200 \mathrm{~A} / \mathrm{cm})$ by introducing pinning: highest for a FF-MOD film ${ }^{[45]}$

\section{Summary}

This paper introduced the following two scenarios and elemental technologies that were employed to achieve the goals to meet the product requirements for the technology for a high-quality, large-area superconducting film by the MOD method for the purpose of FCL application.

I. Verification of YBCO thin film manufacturing and achievement of high $J_{c}$

II. Deposition of a high- $J_{c}$, large-area YBCO film

In Scenario I, the main topic was the preparation of a homogeneous coating solution based on solution chemistry and the development of a low-temperature process using low oxygen pressure that is based on solid physical chemistry. Even though we started from the solution, we obtained a high $-J_{c}$ film that grew epitaxially on the substrate.

On the other hand, in Scenario II, the approach taken was first contemplating the enlargement of the YBCO film on the lattice-matched substrate, II-1, and, concurrently, conducting the manufacture of the buffer layer on latticemismatched sapphire and the tuning of YBCO deposition, II-2. Afterwards, a large surface area was achieved for the superconducting/buffer/sapphire multilayers, II-3. In executing this approach according to the development plan, there were researchers who were specialists of gas phase deposition and those who specialized in liquid phase deposition within the group, and the two sets of researchers collaborated and offered good feedback. It was also crucial that we were able to procure manufacturing and evaluation devices that could handle large substrates at the appropriate time.

These approaches are utilized in the applications to microwave devices and wire rods and tapes.

\section{Acknowledgements}

We are deeply thankful to the Power and System Laboratory of the Furukawa Electric Co., Ltd. that provided us with the photographs of the FCL test. We also thank all the people of the R\&D Joint Research Committee of the R\&D for Practical Superconducting FCL.

\section{References}

[1] New Energy and Industrial Technology Development Organization: R\&D of the Core Technology for Superconducting AC Equipment, Fact Sheet, I-2-I-6 (2005) (in Japanese). http://www.nedo.go.jp/content/100091370.pdf

[2] T. Okuma and Y. Iwata: Superconducting fault current limiter, J. Inst. Elect. Engnr. Jpn., 117 (4), 222-226 (1997) (in Japanese).

[3] S. Mizuta, T. Kumagai and T. Manabe: Preparation of superconducting films by dipping-pyrolysis process, $J$. Chem. Soc. Jpn. 1, 11-23 (1997) (in Japanese).

[4] I. Yamaguchi, T. Manabe, T. Kumagai and S. Mizuta: Preparation of epitaxial oxide films by the coating-pyrolysis process, J. Magn. Soc. Jpn., 24 (8), 1173-1180 (2000) (in Japanese).

[5] T. Araki, K. Yamagiwa and I. Hirabayashi: Fabrication of YBCO films by metalorganic deposition using trifluoroacetates and its process conditions, Journal of Cryogenics and Superconductivity Society of Japan, 35 (11), 516-522 (2000) (in Japanese).

[6] K. Ueda, K. Yasuda, K. Inoue, A. Kikuchi and K. Iwadate: R\&D of HTS power cable and fault current limiter in SuperACE project, Physica C, 392-396, 1171-1179 (2003).

[7] New Energy and Industrial Technology Development Organization: $R \& D$ of the Core Technology for Superconducting AC Equipment, Fact Sheet, Basic Plan 1 (2005) (in Japanese). http://www.nedo.go.jp/content/100091370.pdf

[8] G. Kästner, D. Hesse, M. Lorenz, R. Scholz, N.D. Zakharov and P. Kopperschmidt: Microcracks observed in epitaxial thin films of $\mathrm{YBa}_{2} \mathrm{Cu}_{3} \mathrm{O}_{7-\delta}$ and $\mathrm{GdBa}_{2} \mathrm{Cu}_{3} \mathrm{O}_{7-\delta}$, Phys. Stat. Sol. (a), 150 (1), 381-394 (1995).

[9] M. Kawasaki: Thin-film technology for high- $T_{c}$ superconducting devices, J. Cryo. Soc. Jpn., 31 (11), 563-571 
(1996) (in Japanese).

[10] H. Kinder, P. Berberich, W. Prusseit, S. Rieder-Zecha, R. Semerad and B. Utz: YBCO film deposition on very large areas up to $20 \times 20 \mathrm{~cm}^{2}$, Physica $C, 282-287$ (1), 107-110 (1997).

[11] C. Hoffmann, A. Lümkemann, U. Schmatz, M. Bauer, R. Metzger, P. Berberich and H. Kinder: $\mathrm{YBa}_{2} \mathrm{Cu}_{3} \mathrm{O}_{7-\mathrm{x}}$ deposition of large moving plates for continuous processing, IEEE Trans. Appl. Supercond., 13 (2), 2879-2881 (2003).

[12] B. Schey, W. Biegel, M. Kuhn and B. Stritzker: Large area pulsed laser deposition of YBCO thin films, IEEE Trans. Appl. Supercond., 9 (2), 2359-2362 (1999).

[13] J. Geerk, F. Ratzel, H. Rietschel, G. Linker, R. Heidinger and R. Schwab: Simultaneous double-sided deposition of HTS films on 3-inch wafers by ICM-sputtering, IEEE Trans. Appl. Supercond., 9 (2), 1543-1546 (1999).

[14] T. Kumagai, H. Yokota, K. Kawaguchi, W. Kondo and S. Mizuta: Preparation of superconducting $\mathrm{YBa}_{2} \mathrm{Cu}_{3} \mathrm{O}_{7-\delta}$ (YBCO) thin films by the dipping-pyrolysis process using organic acid salts, Chem. Lett., 1987 (8), 1645-1646 (1987).

[15] T. Manabe, H. Yokota, T. Kumagai, W. Kondo and S. Mizuta: Preparation of superconducting $\mathrm{Ba}_{2} \mathrm{YCu}_{3} \mathrm{O}_{7-\delta}$ films by the dipping-pyrolysis process using metal laurates, JCSJapan, 98 (2), 220-224 (1990) (in Japanese).

[16] T. Kumagai, W. Kondo, H. Yokota, H. Minamiue and S. Mizuta: Preparation of superconducting $\mathrm{YBa}_{2} \mathrm{Cu}_{3} \mathrm{O}_{7-\delta}$ films by the dipping-pyrolysis process using metal acetylacetonates, Chem. Lett., 1988 (3), 551-552 (1988).

[17] K. Kishio, J. Shimoyama, T. Hasegawa, K. Kitazawa and K. Fueki: Determination of oxygen nonstoichiometry in a high$T_{c}$ superconductor $\mathrm{Ba}_{2} \mathrm{YCu}_{3} \mathrm{O}_{7-\delta}$, Jpn. J. Appl. Phys., 26 (7), L1228-L1230 (1987).

[18] T. Kumagai, T. Manabe, W. Kondo, H. Minamiue and S. Mizuta: Effects of heat treatment conditions on the critical current densities of $\mathrm{Ba}_{2} \mathrm{YCu}_{3} \mathrm{O}_{7-\mathrm{y}}$ films prepared by the dipping-pyrolysis process, Jpn. J. Appl. Phys., 29, L940-L942 (1990).

[19] T. Manabe, W. Kondo, S. Mizuta and T. Kumagai: Preparation of high- $J_{c} \mathrm{Ba}_{2} \mathrm{YCu}_{3} \mathrm{O}_{7-\mathrm{y}}$ films on $\mathrm{SrTiO}_{3}(100)$ substrates by the dipping-pyrolysis process at $750{ }^{\circ} \mathrm{C}, \mathrm{Jpn} . \mathrm{J}$. Appl. Phys., 30 (9B), L1641-L1643 (1991).

[20] T. Manabe, K. Arai, W. Kondo, S. Mizuta and T. Kumagai: Preparation of $\mathrm{YBa}_{2} \mathrm{Cu}_{3} \mathrm{O}_{7-\mathrm{y}}$ films on $\mathrm{SrTiO}_{3}$ and $\mathrm{MgO}$ by the dipping-pyrolysis process under low- $p\left(\mathrm{O}_{2}\right)$ heat treatment, $J$. Mater. Res., 7 (9), 2337-2342 (1992).

[21] T. Kumagai, T. Manabe, W. Kondo, S. Mizuta and K. Arai: Preparation of high $J_{c} \mathrm{Ba}_{2} \mathrm{YCu}_{3} \mathrm{O}_{7-\mathrm{y}}-\mathrm{Ag}$ composite films on $\mathrm{SrTiO}_{3}(100)$ substrates by the dipping-pyrolysis process, Appl. Phys. Lett., 61 (8), 988-990 (1992).

[22] T. Kumagai, H. Yamasaki, K. Endo, T. Manabe, H. Niino, T. Tsunoda, W. Kondo and S. Mizuta: Critical current densities at $77 \mathrm{~K}$ in $\mathrm{Ba}_{2} \mathrm{YCu}_{3} \mathrm{O}_{7-\mathrm{y}}-\mathrm{Ag}$ films prepared by dippingpyrolysis process, Jpn. J. Appl. Phys., 32 (11A), L1602-L1605 (1993).

[23] T. Manabe, W. Kondo, S. Mizuta and T. Kumagai: Crystallization of $\mathrm{YBa}_{2} \mathrm{Cu}_{3} \mathrm{O}_{7-\mathrm{y}}$ films on $\mathrm{SrTiO}_{3}(100)$ by postannealing of precursors prepared by dipping-pyrolysis process, J. Mater. Res., 9 (4), 858-865 (1994).

[24] T. Manabe, I. Yamaguchi, W. Kondo, S. Mizuta and T. Kumagai: Processing of superconducting films and tapes by dipping-pyrolysis process, in K. Yamafuji and T. Morishita (eds.), Advances in Superconductivity VII /2, Springer, 589594 (1994).

[25] M. Mukaida and S. Miyazawa: Nature of preferred orientation of $\mathrm{YBa}_{2} \mathrm{Cu}_{3} \mathrm{O}_{\mathrm{x}}$ thin films, Jpn. J. Appl. Phys., 32,
4521-4528 (1993).

[26] T. Manabe, W. Kondo, I. Yamaguchi, M. Sohma, T. Tsuchiya, K. Tsukada, S. Mizuta and T. Kumagai: Critical current density and microwave surface resistance of $5-\mathrm{cm}$ diameter YBCO films on $\mathrm{LaAlO}_{3}$ substrates prepared by MOD using an infrared image furnace, Physica $C$, 417, 98102 (2005).

[27] T. Manabe, M. Sohma, I. Yamaguchi, K. Tsukada, W. Kondo, K. Kamiya, T. Tsuchiya, S. Mizuta and T. Kumagai: Surface resistances of 5-cm-diameter YBCO films prepared by MOD for microwave applications, Physica $C, 445-448$, 823-827 (2006).

[28] M. Sohma, I. Yamaguchi, K. Tsukada, W. Kondo, S. Mizuta, T. Manabe and T. Kumagai: Cerium oxide $\left(\mathrm{CeO}_{2}\right)$ buffer layers for preparation of high- $J_{c}$ YBCO films on large-area sapphire substrates $(30 \mathrm{~cm} \times 10 \mathrm{~cm})$ by coating pyrolysis, Physica C, 412-414, 1326-1330 (2004).

[29] M. Sohma, I. Yamaguchi, K. Tsukada, W. Kondo, K. Kamiya, S. Mizuta, T. Manabe and T. Kumagai: Preparation of $\mathrm{CeO}_{2}$ buffer layers for large-area MOD-YBCO films $(10 \times$ $30 \mathrm{~cm}^{2}$ ) with high- $J_{c}$, IEEE Trans. Appl. Supercond., 15 (2), 2699-2702 (2005).

[30] T. Manabe, M. Sohma, I. Yamaguchi, W. Kondo, K. Tsukada, S. Mizuta and T. Kumagai: 2-D large-size YBCO films on sapphire for FCL prepared by coating-pyrolysis process, Physica C, 392-396, 937-940 (2003).

[31] T. Manabe, M. Sohma, I. Yamaguchi, W. Kondo, K. Tsukada, K. Kamiya, S. Mizuta and T. Kumagai: Distribution of inductive $J_{c}$ in two-dimensional large-size YBCO films prepared by fluorine-free MOD on $\mathrm{CeO}_{2}-$ buffered sapphire, IEEE Trans. Appl. Supercond., 15 (2), 2923-2926 (2005).

[32] T. Manabe, M. Sohma, I. Yamaguchi, W. Kondo, K. Tsukada, S. Mizuta and T. Kumagai: Preparation of high- $J_{c}$ large-size YBCO films $\left(30 \times 10 \mathrm{~cm}^{2}\right)$ by coating-pyrolysis process on $\mathrm{CeO}_{2}$-buffered sapphire, Physica $C, 412-414$, 896-899 (2004)

[33] K. Osamura and K. Matsumoto: Development of practical high-temperature superconducting conductors and their future trends, Oyo Buturi, 73 (1), 3-13 (2004) (in Japanese).

[34] H. Yamasaki, M. Furuse and Y. Nakagawa: High-powerdensity fault-current limiting devices using superconducting $\mathrm{YBa}_{2} \mathrm{Cu}_{3} \mathrm{O}_{7}$ films and high-resistivity alloy shunt layers, Appl. Phys. Lett., 85, 4427-4429 (2004).

[35] T. Nitta, T. Matsumura, J. Baba, M. D. Ainslie, S. Torii, H Kado, T. Kumagai and M. Shibuya: Tests for conceptual design of $6.6 \mathrm{kV}$ class superconducting fault current limiter with YBCO thin film elements, IEEE Trans. Appl. Supercond., 19 (3), 1964-1967 (2009).

[36] H. Yamasaki, K. Arai, K. Kaiho, Y. Nakagawa, M. Sohma, W. Kondo, I. Yamaguchi, H. Matsui, T. Kumagai, N. Natori and N. Higuchi: $500 \mathrm{~V} / 200$ A fault current limiter modules made of large-area MOD-Y $\mathrm{Ba}_{2} \mathrm{Cu}_{3} \mathrm{O}_{7}$ thin films with highresistivity $\mathrm{Au}-\mathrm{Ag}$ alloy shunt layers, Supercond. Sci. Tech., 22 (12), 125007 (2009).

[37] H. Yamasaki, K. Arai, M. Furuse, Y. Nakagawa, K. Kaiho, T. Kumagai, M. Shibuya and T. Nitta: Comparison of estimated conductor costs between a superconducting thinfilm fault-current limiter (FCL) and a coated-conductorbased superconducting FCL, J. Cryo. Jpn., 41 (9), 397-404 (2006) (in Japanese)

[38] K. Setsune and A. Enokihara: Application of high- $T_{c}$ superconductors for mobile telecommunication systems: Microwave filters for base stations, Oyo Buturi, 66 (4), 351355 (1997) (in Japanese). 
[39] N. Sakakibara: Compact high-temperature superconductor filter, Oyo Buturi, 72 (1), 21-26 (2003) (in Japanese).

[40] T. Kumagai, T. Manabe, I. Yamaguchi, S. Nakamura, W. Kondo, S. Mizuta, F. Imai, K. Murayama, A. Shimokobe and Y-M. Kang: Preparation of YBCO films by CP-process for HTS microwave filters, in T. Yamashita and K. Tanabe (eds.), Advances in Superconductivity XII, Springer, 927-929 (2000).

[41] T. Kumagai, T. Manabe, W. Kondo, K. Murayama, T. Hashimoto, Y. Kobayashi, I. Yamaguchi, M. Sohma, T. Tsuchiya, K. Tsukada and S. Mizuta: Characterization of 50-mm-diameter Y123 films prepared by a coating-pyrolysis process using an infrared image furnace, Physica $C, 378$ 381, 1236-1240 (2002).

[42] M. Sohma, K. Kamiya, K. Tsukada, I. Yamaguchi, W. Kondo, S. Mizuta, T. Manabe and T. Kumagai: Fabrication of double-sided $\mathrm{YBa}_{2} \mathrm{Cu}_{3} \mathrm{O}_{7}$ films on $\mathrm{CeO}_{2}$-buffered sapphire substrates by MOD process, IEICE Trans. Electron., E89-C (2), 182-185 (2006).

[43] M. Sohma, T. Tsuchiya, K. Tsukada, I. Yamaguchi, T. Manabe, T. Kumagai, K. Koyanagi, T. Ebisawa and H. Ohtsu: Preparation of epitaxial YBCO films by a novel excimer-laser-assisted MOD, IEEE Trans. Appl. Supercond., 17 (2), 3612-3615 (2007).

[44] I. Yamaguchi, W. Kondo, T. Hikata, K. Kamiya, H. Matsui, M. Sohma, K. Tsukada, Y. Nakagawa, T. Kumagai and T. Manabe: Preparation of Y123 thick films by fluorine-free MOD using a novel solution, IEEE Trans. Appl. Supercond., 21 (3), 2775 -2778 (2011).

[45] H. Matsui, H. Ogiso, H. Yamasaki, T. Kumagai, M. Sohma, I. Yamaguchi and T. Manabe: 4-fold enhancement in the critical current density of $\mathrm{YBa}_{2} \mathrm{Cu}_{3} \mathrm{O}_{7}$ films by practical ion irradiation, Appl. Phys. Lett., 101 (23), 232601 (2012).

\section{Authors}

\section{Takaaki MANABE}

Graduated from the Department of Synthetic Chemistry, School of Engineering, The University of Tokyo in 1988. Joined the National Chemical Laboratory for Industry, Agency of Industrial Science and Technology in 1988. Leader, Thin Films Processing Research Group, Advanced Manufacturing Research Institute, AIST in 2009. Chief Planning Officer, Compliance

Headquarter, AIST (also worked at the Advanced Manufacturing Research Institute) in 2014. Winner of Contribution Award of the Ichimura Prize in Technology, Progress Award of the Ceramic Society of Japan, and others. Engages in the synthesis of worldclass large-area superconducting film and its application to FCL. In this paper, was mainly in charge of Scenario II.

\section{Mitsugu SoHMA}

Completed the master's course at the Department of Applied Chemistry, Graduate School of Engineering, Hokkaido University in 1989. Joined the National Chemical Laboratory for Industry, Agency of Industrial Science and Technology in 1989. Obtained the doctorate degree (Engineering) for research in magnetic thin film in 1996. Senior Researcher,

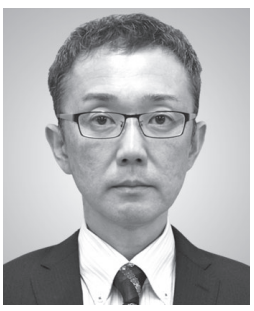
Institute for Materials and Chemical Process, AIST in 2001.
Leader, Thin Films Processing Research Group, Advanced Manufacturing Research Institute, AIST in 2014. In this paper, engaged in the synthesis of high-quality buffer layer suitable for superconducting film and the application of high-performance thin film to superconducting film by the coating irradiation method.

\section{Iwao YAMAGUCHI}

Completed the master's course at the Graduate School of Engineering, Kyoto University in 1994. Joined the National Chemical Laboratory for Industry, Agency of Industrial Science and Technology in 1994. Worked at the Inorganic Materials Section at NCLI; Institute for Materials and Chemical Process, AIST; and currently, Senior Researcher, Advanced

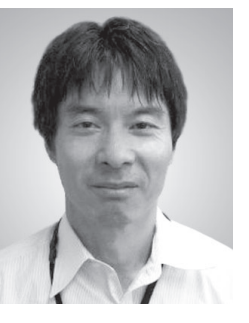
Manufacturing Research Institute, AIST. Obtained the doctorate (Engineering) at the Graduate School of Engineering, Kyoto University in 2009. In this paper, engaged in the synthesis and evaluation of the epitaxial thin film of superconductors and various oxides, as well as the thick film manufacturing process and its application to superconducting tape.

\section{Hiroaki MATSUI}

Completed the doctorate at the Graduate School of Science, Tohoku University in 2006. After Assistant Professorship at the Tohoku University, joined AIST in 2008. Currently, Senior Researcher, Advanced Manufacturing Research Institute, AIST. Doctor (Science). In this paper, engaged in the synthesis of high-performance superconducting film by coating irradiation method, and the clarification of mechanism for generating highdensity critical current by nanostructure control.

\section{Tetsuo TsuchiYA}

Completed the doctorate at the Graduate School of Science and Technology, Tokyo University of Science in 1998. After COE Fellowship at the National Institute of Materials and Chemical Research, Agency of Industrial Science and Technology, joined AIST in 2000; and Leader, Flexible Chemical Research Group, Advanced Manufacturing Research Institute, AIST in 2010. Doctor

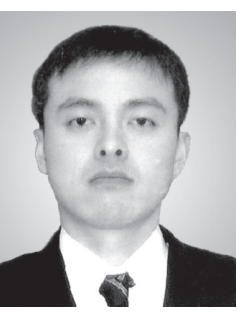
of Engineering. Got the idea for crystal growth for functional thin films by laser-assisted MOD in 1999. Since then, developed the flexible thin film methods by low-temperature multicrystal growth of metal oxides by photodecomposition of metal organic compounds, epitaxial growth, and nano-particle photoreaction. In this paper, engaged in the development of manufacturing process of superconductor by coating irradiation method.

\section{Toshiya Kumagai}

Graduated from the Department of Applied Chemistry, School of Science and Engineering, Waseda University in 1974. Joined the National Chemical Laboratory for Industry, Agency of Industrial Science and Technology in 1975; Group Leader, AIST in 2001; Deputy Director, Advanced Manufacturing Research Institute, AIST in 2009; and currently, Invited Senior

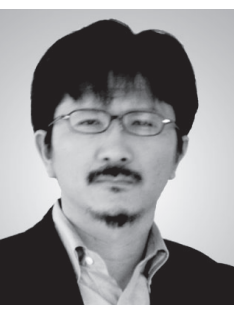
Researcher. Doctor (Engineering). Winner of Contribution 
Award of the Ichimura Prize in Technology and others Engaged in the inorganic materials science research mainly for energy related applications. Succeeded for the first time in the world to synthesize the YBCO superconducting film using this method in 1987, and led the R\&D for its synthesis and application. In this paper, was mainly in charge of Scenario I.

\section{Discussions with Reviewers}

\section{Overall}

Comment (Hiroshi Akoh, Thermal Management Materials and Technology Research Association)

This paper focuses on the target of electrical application of a high-temperature oxide superconductor to the fault current limiter, and builds the scenario for its development and shows the selection and combination of the elemental technologies. I think it is valuable as a Synthesiology paper.

Comment (Tetsuhiko Kobayashi, AIST)

This paper is about the creation of a large-area superconducting film for application to FCL, and I recommend its publication in the journal.

\section{Explanation of FCL}

Question and Comment (Hiroshi Akoh)

In this paper, the development of FCL is given as the electric power application of high-temperature oxide superconductors. Therefore, I think it is important to show a diagram that allows the readers outside the field to grasp the image of FCL. In the paper, the structure and operational principle of FCL are shown in diagrams, and it is described in the text in chapter 2 , however I think readers can more easily understand if you present a figure that shows the role and importance of FCL in the power grid system. Also, I think you can clarify the correspondence to the photograph of the device which includes the prototype FCL shown in Fig. 8 .

Moreover, there is a description of "development of many types of FCLs" in chapter 1, however I think you should clarify by giving specific examples of other types of FCLs.

Answer (Toshiya Kumagai)

I added a figure that shows the role of FCL in the power grid system as Fig. 1, and inserted in the upper part of Fig. 2 a figure that shows the "FCL cooled in the cryostat" that shows correspondence to the photo of the device in Fig. 8.

I added a few examples of active and passive FCLs in chapter 2.

\section{Relationship of Scenarios I and II}

\section{Question and Comment (Hiroshi Akoh)}

I understand that Scenarios I and II are continuously related toward the development of FCL, however the relationship of Scenarios I and II seems to become unclear since you explain them separately in Figs. 4 and 5. I think the main point of this paper is that you succeeded in achieving high $T_{c}$ and high $J_{c}$ by the MOD method, and using that as core technology and advancing the R\&D to achieve a large-area film and multilayer, there was considerable progress in the FCL development. I think the scenario continues to mention that the application can extend to microwave devices by achieving low surface resistance and patterning, and in the future it can be applied to superconducting wires by achieving the long length and thick thickness. What do you think of the scenario where you discuss mainly the development of FCL and then spreading out to microwave devices and superconducting wire applications?

Answer (Toshiya Kumagai and Takaaki Manabe)

The scenario of the whole paper and its main point are as you indicated. However, describing the research in chronological order, it was still unclear that FCL was the outlet when we were setting Scenario I (at the time of discovery of the hightemperature superconductor). The application to various electric power devices was a "dream," and in reality, we conducted R\&D for "high $J_{c}$ " as the essential goal to realize that dream. Later, when we achieved high $J_{c}$, we could regard various devices including FCL as specific targets, and only then did we set the goal to fulfill the product requirements, build the scenario to achieve them, and then engaged in the R\&D. In this paper, we focus on the application to FCL, but we have concurrently worked on the application to microwave devices to some extent. Considering these points, we shall describe Scenarios I and II separately in the figures. In Fig. 5, we specify that the "success of epitaxial deposition and achievement of high $J_{c}$ " in I-2 are the core technologies in Scenario II.

\section{Characteristic of the MOD method}

Question and Comment (Tetsuhiko Kobayashi)

You describe in subchapter 1.2 as one of the characteristics of MOD that "(4) it has low environmental load since it emits only steam and carbon dioxide during firing," but aren't VOC and incomplete combustion gas produced depending on the condition? Answer (Takaaki Manabe)

As you indicated gases such as VOC may be produced in incomplete combustion. Also, this item is not a characteristic of the MOD method compared with the gas phase method, but is the characteristic of the FF-MOD method using fluorine-free materials that was employed in this paper, in contrast to the TFAMOD method that uses trifluoroacetate as the raw material. I added and revised item 4 to make this clear to the readers.

\section{Infrared rapid heating process}

\section{Question and Comment (Hiroshi Akoh)}

This is a technical question. As you describe in chapter 5, you developed the rapid heating process by infrared heating to inhibit the $a$-axis oriented growth and to obtain the $c$-axis oriented film. Were there any cracks in the film due to the difference in thermal expansion coefficients of the substrate and the film? Please explain if there were no cracks.

\section{Answer (Takaaki Manabe)}

No cracks occurred by rapid heating for the YBCO film with thickness of $700 \mathrm{~nm}$ on LAO. I explained that it is because they are lattice matched and their thermal expansion coefficients are close.

Also, the film on sapphire that has large thermal expansion difference tends to get micro-cracks during cooling after deposition, and the thickness of the YBCO film is limited to 300 $\mathrm{nm}$ or less. I added this in chapter 2.

\section{Achievement of a large-area thin films and a low- temperature process \\ Question and Comment (Tetsuhiko Kobayashi)}

To achieve a large-area thin films, you say, "a low-temperature process was developed to increase the $J_{c}$ by decreasing the interface reaction between the film and the substrate and by improving the orientation." For readers outside the field, the meaning of "decreasing the interface reaction between the film and the substrate" is difficult to understand, and I think you need some supplementary explanation.

\section{Answer (Takaaki Manabe)}

Including the point that you indicated, the description of the draft was not well organized, so I changed the description to the following: the chemical reaction occurs at the interface between the YBCO film and the substrate when the firing temperature is high $\rightarrow$ a low-temperature process was developed to inhibit the interface reaction $\rightarrow$ this low temperature allowed use of lattice-matched substrates $\rightarrow$ orientation of the YBCO film was improved using the lattice-matched substrate. 